\title{
José Luis Pellicer, corresponsal artístico en la última guerra carlista
}

\author{
maria dolores Bastida de la Calle
}

Un artista alto, desgarbado, de enormes cejas, bigotes y barba abundantes, y rictus cansado - tal es la descripción que de él hace Salvador Bori-' 'va a la guerra de corresponsal gráfico. El artista es el barcelonés José Luis Pellicer, el medio La llustración Española y Americana, la guerra el conflicto carlista que asola España de 1872 a 1876. Las páginas de la llustración se ven enriquecidas en esos años con los dibujos y sketches de Pellicer, tomados directamente en el campo de batalla, del lado liberal. Como en toda Europa se sabia, una "buena» guerra vendía más copias de una revista que cualquier otro acontecimiento, y la imagen era parte esencial de la información: "Deben ser los periódicos ilustrados no sólo crónicas escritas sino también crónicas fotográficas, donde aparezcan exactas descripciones y reproducciones de esos grandes acontecimientos que tienen el privilegio de excitar en alto grado la atención del público" (IEA, marzo 8, 1874). Pellicer resultó ser en verdad una notable (y sensible) "cámara fotográfica", el único español al que cabe llamar "Special Artist".

El término "Special Artist» fue usado por vez primera en The llustrated London News, pionero de la información gráfica, para designar a los seis dibujantes (Constantin Guys entre ellos) que envió a cubrir la guerra de Crimea (1853-56). Ya no era posible utilizar los servicios de artistas locales, como en la Revolución de 1848 en París, ilustrada en la revista londinense con dibujos realizados in situ por Guys y Gavarni entre otros ${ }^{2}$.

\footnotetext{
1 Salvador Bonl, Tres Maestros del Lápiz de la Barcelona Ochocentista; Padró, Planas, Pellicer. Barcelona, Librería Millá, 1945, pág. 64.

2 Paul HOGARTH, The artist as reporter. Londres, Gordon Fraser, 1986, pág. 30.
} 
$Y$ aunque oficiales combatientes y viajeros ocasionales solian enviar croquis desde los campos de batalla, no podian satisfacer las crecientes exigencias de los lectores, tanto en el número como en la urgencia de los envios. La profesión de "Special Artist" ( $y$ el término en el habla inglesa) tomó asi cuerpo entre lectores y editores de todo Occidente.

El final del siglo XIX fué la época dorada de los ilustradores de noticia bélica. Como se ha dicho, "los corresponsales de guerra, dibujantes y reporteros, llegaron a ser la élite de la profesión periodística y desarrollaron una personalidad de grupo jactanciosa, tipo Hemingway, que ellos exhibían en público" ${ }^{3}$ : A. Waud en la guerra de Secesión norteamericana, W. Simpson en la de Crimea, Melton Prior y F. Villiers en las Coloniales británicas. Con José Luis Pellicer se repite la imagen del corresponsal con un buen caballo, anteojos, cuadernos de notas, y lápices, aunque en él (serio, introvertido, comprometido socialmente) no haya nada de jactancia.

Mientras que la labor de Pellicer en la ilustración de libros, revistas satíricas o crónicas de la guerra ruso-turca ha sido generalmente elogiada y en alguna medida estudiada ${ }^{4}$, apenas si lo han sido sus grabados sobre la querra carlista, que se analizan aquí con el propósito de rastrear ciertos aspectos y condicionantes de su vida y personalidad: Se sabe que llegó al dibujo de noticia tras su fracaso en la pintura, y especialmente en el manejo del color; $y$ de su ascenso social desde un origen humilde (hijo de albañil), con una preocupación por los temas sociales y por mostrarlos tal como eran.

\section{LA TRAYECTORIA DE PELLICER EN EL REPORTAJE BÉLICO}

La carrera de José Luis Pellicer como "Special Artist" fué rápida y breve. Durante los primeros años de la guerra carlista, 1872 y 1873 , fué dibujante de estudio, lo que los ingleses llamaban "Staff Artist»; en las revistas francesas el "Staff Artist" era una figura de prestigio: Gustavo Doré en la guerra de Crimea, y Daniel Vierge en la guerra carlista misma,

3 Pat Hodgson, The War Illustrators. Londres, Osprey, 1977, Introduction

4 Valeriano Bozal, La ilustración gráfica del siglo xix en España. Madrid, Comunicación, 1979; Francesc FontBona: "La liustración Gráfica. Las técnicas fotomecánicas", El Grabado en España (siglos XIX y XX), Summa Artis, Vol. XXXII. Madrid, Espasa Calpe, 1988. 
dibujaron escenas de combate para L'Illustration y Le Monde Illustré respectivamente, a partir de informes y croquis de testigos presenciales. Sin embargo, Pellicer muestra ya en esos años un creciente interés por el dibujo natural, tanto de tema social como militar, viajando repetidamente entre Madrid y Barcelona (Apuntes de viaje por Pellicer, IEA, octubre 24, 1873). Y ya al final de 1873, en las revueltas Cantonales, realiza dibujos in situ como corresponsal especial de la Ilustración Española y Americana, en el campamento de la Palma; el publicado el 16 de diciembre "Sitio de Cartagena: Apuntes tomados sobre el terreno por nuestro colaborador artístico", es una magnífica perspectiva de una bateria costera.

Sería en 1874, sin embargo, cuando se le envía al Norte a cubrir la guerra carlista como dibujante corresponsal; un grabado con fecha 8 de marzo, muestra la "Llegada de nuestro artista al puente sobre la ría de Guriezo, incendiada por la facción Navarrete" (Fig. 1). El tratamiento que se le dá inicialmente «Acontecimientos militares en el Norte, apuntes remitidos por nuestro 'especial artista', Sr. de Pellicer", sugiere a través del anglicismo, la intención de la revista de emular a los grandes semanarios ilustrados de Londres y Nueva York. El 22 de marzo se le llama ya "artista especial». Pero es a partir del número siguiente, marzo 30 , cuando se abandona definitivamente el uso del adjetivo especial. Se mencionan, por ejemplo, los "Apuntes de la campaña del Norte por el Sr. Pellicer", "Dibujos del Natural por Pellicer", o "Apuntes remitidos por nuestro corresponsal artístico Sr. Pellicer". Se percibe una gran admiración del editor por su reportero, quien hacía olvidar a los "Special Artists" extranjeros. Sabemos de la notable reputación que adquirió entre público y profesionales; y el énfasis en términos como "apuntes" o «del natural», señala claramente un rasgo esencial de su arte. Salvador Bori decia "que el culto que rendía al natural, era casi una obsesión" ${ }^{5}$.

Su colaboración en revistas extranjeras se inició en los años 1873, 1875 y 1876, en el semanario inglés The Graphic, alternativa liberal al IIIustrated London News. En la primera mitad del 73, el "Special Artist" del Graphic en el conflicto había sido el francés Géry Bichard. No se menciona a Bichard, sin embargo, en las ilustraciones sobre la guerra de la segunda mitad, todas de ambiente catalán. Es muy posible que la totalidad de esas ilustraciones sean de Pellicer; con seguridad lo son las de octubre 25 , noviembre 8 y julio 26 que llevan su firma (la última algo confusa). La revista alude en alguna crónica a "our special artist in Spain". En 1875 publica en The Graphic, con fecha marzo 20, un sketch

5 Salvador Borl: Tres maestros ..., pág. 78. 
de un reciente viaje a Navarra (Types of the Alphonsist troops) y el 4 de marzo de 1876, aparece su estampa "A sketch during the battle of Elgueta" tomada en el frente. La revista utiliza en ambos casos el tratamiento de «our artist".

En el mismo año de 1876, Pellicer establece una breve colaboración con el semanario francés Le Monde Illustré, como "correspondant spécial", con dibujos en febrero 12, "Campement des troupes alphonsistes au pied de la redoute de Caceres (Navarre)" (Fig. 2), febrero 19 y 26, y marzo 4 («Les Carlistes, battus à Montejurra, transportent leurs blessés a l'hôpital d'Irache" y "Prise de la redoute carliste de Montejurra par les brigades Cortijo et Moreno-Villar»).

Al estallar la guerra ruso-turca de 1877 la Ilustración Española y Americana le envía al frente acompañando a las fuerzas del general ruso Gurko ${ }^{6}$. Este fué, sin embargo, el final de su carrera como corresponsal artístico, que había durado apenas cuatro años. En 1878, un cuadro y dibujos basados en su estancia en Oriente, le permiten ganar una medalla de tercera clase en la Exposición de Bellas Artes: era usual que un artista utilizase apuntes tomados en el frente para realizar con posterioridad cuadros "formales" (recuérdense los lienzos de Ricardo Balaca, "Los Navarros" y "La Batalla de Treviño" sobre la guerra carlista) o libros de estampas litográficas (por ejemplo, «The Seat of the War in the East" de W. Simpson, sobre la guerra de Crimea). Todavía en 1881 Pellicer colabora en París, en revistas francesas e inglesas ${ }^{7}$, pero lejos del frente para siempre.

Como otros famosos corresponsales gráficos (citemos a Melton Prior del Illustrated London News y Dick de Lonlay en Le Monde IIlustré), Pellicer también enviaba cortas crónicas en las que describia el contenido de sus dibujos, enfatizando el mensaje icónico y la información. El editor de la Ilustración Española y Americana alude admirativamente a «...los curiosos apuntes que acompañan a los croquis, debidos también, como éstos, al Sr. Pellicer, y escritos con la fidelidad e imparcialidad convenientes" (marzo 15, 1874).

Un leit motiv de esas crónicas es la consciencia y el orgullo de su nuevo oficio, al que se entrega plenamente tras su fracaso en la pintura. Este orgullo se manifiesta en la repetida alusión a otros enviados espe-

6 La Guerra Ruso-Turca de 1876-78 en los grabados de José Luis Pellicer. Madrid, Club Urbis, 1978.

7 Conrat Roure, "Joseph Lluis Pellicer", La llustraçió Catalana. Núm. 51, Noviembre 1881, pág. 414-415. 
ciales: “Cúmpleme decir que La llustración Española y Americana es el primer periódico que ha tenido representación personal en el ejército del Norte en la presente campaña; más posteriormente he tenido la satisfacción de saludar aquí a los Sres. Araus y Alcázar del Imparcial, Romera de la Política. Figueroa de la Bandera Española; Mr. Coutouly de Le Temps de París y a otros dos corresponsales, cuyos nombres siento ignorar, de L'independence belge de Bruselas y de un periódico de Londres" (IEA, marzo 22, 1874). En algún caso Pellicer se complace en dibujarlos ("Corresponsales de la prensa nacional y extranjera agregados al cuartel general del ejército del Norte, mayo 22, 1874») (Fig. 3). La llegada masiva de enviados especiales de prensa, Pellicer entre ellos, se inició a finales de febrero de 1874, con la campaña del Valle de Somorrostro y la toma del mando del ejército del Norte por el general Serrano que acudia en defensa de Bilbao; es entonces cuando puede decirse que los corresponsales, "tratados con la mayor consideración por todos los individuos del ejército, desde el general en jefe hasta el último soldado", "empezaron a formar corporación y a estar agregados al cuartel general». En la escena de nieve "Ejército de la izquierda.- Paso de un convoy por el alto de Urquiola, el 8 del actual', febrero 22, 1876 (Fig. 4), Pellicer se incluye de nuevo en la estampa con otros corresponsales «que habian permanecido tres días en Ochandiano esperando ocasión oportuna para incorporarse al cuartel general".

Al comienzo la estancia de los periodistas fué dificil, pero las simpatías personales y la vida de campaña pronto la aliviaron. En la caseta del portazgo del pueblo de la Rigada, con una superficie de tres metros de largo por dos de ancho, estableció la prensa su primer cuartel general, al que llamaron Hotel de las cuatro naciones por alojarse allí reporteros de España, Francia, Bélgica y Suiza. Las dificultades para dibujar y escribir en tan pequeño espacio les obligaron a construir una primitiva tienda de campaña («La Barraca de los periodistas en la Rigada», mayo 22,1874 ) (Fig. 5), que vino a ser como el estudio o gabinete de trabajo.

Como carga normal de su profesión ${ }^{8}$, Pellicer compartió a menudo los riesgos y penalidades de los soldados. La descripción con que el editor del Graphic acompaña al grabado "A sketch during the battle of Elgueta» (Fig. 6), nos muestra los peligros reales a los que se expuso el artista en su tarea. "El sketch de nuestro artista, M. Pellicer, representa un incidente en el ala derecha del ejército Alfonsino cuando el general

8 Frederic E. RaY, Alfred R. Waud, Civil War Artist. New York, Viking Press, 1974, pág. 28 y 29. 
de brigada Abenis dirigía el ataque que siguió a la captura de la ermita de Buruza "donde" - dice Pellicer- "me habia yo refugiado de las balas del enemigo"». Las penalidades de los soldados aparecen reflejadas tanto en sus ilustraciones "Campamento de las Carreras durante los últimos temporales de lluvia y viento", abril 22, 1874 (Fig. 7), "Avanzada del regimiento de León en los altos de Ochandiano", febrero 15, 1876 (Fig. 8), como en sus crónicas. Sobre las Carreras nos dice como «los soldados de nuestro ejército sufrieron mucho, y principalmente los que ejercian servicio en las avanzadas: unos quedaban medio enterrados en el barro y a gritos pedian auxilio a sus compañeros, otros eran sepultados bajo las destrozadas tiendas, algunos cruzaban a través de la impetuosa corriente en busca de los efectos propios que les arrebataba". En estos comentarios se aprecia el fondo social y critico de la obra de Pellicer que guarda quizá relación con su carácter serio e insatisfecho, marcado por la influencia de Martí Alsina, de quien fué discipulo y con cuya hija se caso en segundas nupcias. Ese fondo social se manifiesta también, a menudo, en la descripción de las tareas humildes de un ejército en guerra («Hornos de campaña en Oteiza», IEA, agosto 15, 1875 y "Depósito de viveres en la iglesia parroquial de Oteiza (Navarra)», IEA, junio 30,1875$)$.

\section{LA PREOCUPACIÓN POR EL CONTROL DE LA OBRA}

Un examen detallado de los grabados en que interviene Pellicer en los periodos $1872-73$ y 1874-76 revela muy claramente la preocupación del artista por la pureza y el control de su obra. En múltiples ocasiones de 1873 (y 1872) la llustración hace referencias a apuntes remitidos por testigos presenciales (Sr. Gálvez, "Heróica defensa de Puigcerdá por los vecinos de la ciudad", abril 24; Sr. de Neira, "Catástrofe en el puente de Viana: el descarrilamiento", septiembre 16; Sr. Cubero, "Insurrección carlista", octubre 8). En todos los casos aparecen en la estampa las firmas de Pellicer y del grabador, Manchon, Capuz y Marichal en los ejemplos anteriores. Es claro que aquél trabajó en ellos activamente como artista de gabinete, retocando croquis usualmente muy someros. En algún caso el croquis se debe a un "apreciable suscritor» ("Ataque $e$ incendio del cuartel de la Guardia Civil en Salas de los Infantes", IEA, septiembre 16, 1872); en algún otro trabajó con una fotografía como punto de partida («El Yacht inglés Deerhound, apresado en aguas de San Sebastián con armas por los carlistas (de fotografia)", IEA, septiembre 16, 1873). 
Pellicer, por tanto, hubo de conocer profundamente la diferencia entre un apunte remitido desde el frente y el dibujo publicado después de haber sido retocado por un artista de gabinete; y esto no sólo si aquél se debia a un dibujante ocasional, sino también en el caso de "Special Artists" como Bichard, a los que la urgencia de los envíos llevaba a veces a indicar en los croquis, con palabras, detalles a rellenar por el dibujante de estudio, en particular en el caso de elementos arquitectónicos repetitivos. Pues bien, hemos encontrado evidencia de que Pellicer se negó a que los originales que remitió a partir de marzo de 1874 , en su nueva situación de corresponsal artístico, sufriesen modificaciones antes de llegar al grabador. Por una parte, en las estampas sólo aparecen los nombres de ambos: no se dá crédito a ningún otro dibujante en la ilustración. Por otra parte, ésta es a menudo simple croquis, o está a medio camino entre el croquis y el dibujo acabado; un ejemplo de estos casos intermedios son las estampas "La tregua: soldados del ejército y soldados carlistas visitándose en la línea de avanzadas", y “La tregua: oficiales carlistas en las avanzadas de Murrieta" abril 15, 1874 (Fig. 9), unos dibujos muy someros de trazo ágil, fresco, vivo, realizado al aire libre. Curiosamente este tipo de dibujo coincide con la etapa de eclosión del impresionismo, "alta pintura" de rasgos muy consonantes. El reportero gráfico debia tener "el hábito de percibir 'a primera vista', de un modo 'impresionista'» ${ }^{9}$, enfrentándose sin mediaciones al medio natural.

Es de interés resaltar, sin embargo, que en la colaboración de Pellicer en Le Monde I/lustré, (grabados de febrero 19 y 26 y marzo 4) se menciona que el dibujo es de Daniel (Urrabieta) Vierge y el croquis de Pellicer. No sabemos si éste transigió en ello por su interés en colaborar en la revista de París, o si ignoraba el destino de sus apuntes dado el brevísimo periodo de su colaboración.

Pero salvada la distorsión que un dibujante de estudio hubiera introducido en el original, quedaban todavia otras etapas hasta su publicación. Conviene recordar aqui que la fotografia de acción fué imposible durante largo tiempo, tanto por la lentitud de la exposición a la luz como por el difícil transporte y manejo de los tipos primitivos de cámaras. Por otra parte, los matices de una fotografía no pudieron ser reproducidos en una revista hasta la introducción del fotograbado de trama en la década de los 80 , y aunque procedimientos de fotograbado de línea, como la zincografia, se usaron tentativamente en los 70 para reproducir dibujos en

9 Juan Antonio Ramirez, Medios de Masas e Historia del Arte. Madrid, Ediciones Cátedra, 1988, pág. 54 . 
ciertos libros (Histoire du Mobilier de Jacquemart en 1876 o el Ariosto de Doré en 1879) ${ }^{10}$, en los semanarios de gran circulación el procedimiento universalmente utilizado para imprimir ilustraciones era el grabado en madera de boj.

La fotografía, sin embargo, se utilizaba ya en la época de la guerra carlista para pasar el dibujo al boj, dibujo que el grabador habría de tallar posteriormente. A este respecto, se lee en La Ilustración Española y Americana de mayo 8, 1875, lo siguiente: "Apenas llegado al campo de la guerra nuestro amigo y discreto corresponsal artístico de la llustración en el Ejército del Norte, el Sr. D. José Luis Pellicer, nos ha remitido los interesantes dibujos que aparecen en las páginas 281 y 284 de este número, tomados del natural, y trasladados con todos sus detalles a la madera por medio de procedimientos fotográficos». Esta técnica de fotografiar dibujos sobre una matriz de boj fué establecida en los 60 , aunque hubo ensayos que datan de 1839 (en The Mirror y The Magazine of Sciences) y 1854 (en Art Journal) ". La madera se empapaba en una disolución de sal, se secaba y se empapaba de nuevo en una solución de nitrato de plata que formaba una capa sensible a la luz donde se hacía el dibujo. El procedimiento tenía las ventajas de permitir tanto variaciones de tamaño como la conservación del dibujo original al evitar el calco, y de producir directamente en la matriz una imagen invertida, condición necesaria para obtener en cada copia la imagen del original.

La última etapa que alejaba al artista del producto final, era la talla xilográfica. Una vez fotografiado el dibujo, la matriz, que estaba formada por pequeños bloques, hasta cuarenta en una página doble, se separaba y repartía entre un equipo de grabadores, trabajando unos como especialistas en figuras, y otros en fondos y otros detalles ${ }^{12}$. En la época de la guerra carlista grababan para La llustración Española y Americana, entre otros, Carretero, Capuz, Laporta, Marichal y Rico, en un taller xilográfico, principal centro en el pais a falta de protección académica, que dirigía Rico. El lenguaje gráfico utilizado por los xilógrafos era a base de cortes continuos en la madera: cortes paralelos y finos para los cielos, y curvos $y$ de distinto grosor para sugerir volumen y profundidad. Esta técnica resalta en la estampa "Batería cubierta en las alturas de Pucheta», abril

10 Eric DE MARE, The Victorian Woodbloc Illustrators. Londres, Gordon Fraser, 1980 , pág. 159.

"Eric dE MARE, The Victorian..., pág. 50.

12 Mason JACKSON, The Pictorial Press: Its origin and progress. Londres, Hurst and Blackett, 1885 , pág. 316 y 317. 
30, 1874 (Fig. 10), que grabó Rico. Se ha juzgado a veces que la técnica condujo a un estilo rutinario e impersonal aunque muy eficaz ${ }^{13}$.

Acabada la grabación los bloques se juntaban para formar la matriz completa, pero a veces el resultado no era todo lo perfecto que debiera ser. Esto se aprecia en la estampa «El duque de la Torre visitando las posiciones del ala derecha del ejército", marzo 30, 1874 (Fig. 11), que describe la visita de inspección del general Serrano a las posiciones de las tropas en el cerro de las Arenillas en las acciones del 24 y 25 de febrero, desde donde había hecho fuego una batería de montaña, y donde una bateria Krupp debía entonces proteger un próximo movimiento de avance. Las líneas blancas verticales que se observan son consecuencia del mal encaje de los bloques. Tales imperfecciones eran debidas a la premura con que el grabador había de trabajar para no añadir retraso al ya normal de los envíos (dos o tres semanas desde la realización del croquis a la publicación). Obsérvese la inversión en la firma del grabador. Éste, normalmente, firmaba en el original recién recibido por lo que su nombre aparecia correctamente en la estampa; si por olvido se veía obligado a hacerlo posteriormente en la matriz, su nombre se vería finalmente invertido.

Las obsesión de Pellicer por controlar su obra se debe sin duda, por una parte, a su afán de pintor por preservar la pureza artística en medio de un proceso industrial como el de las revistas ilustradas; $y$ por otra a su realismo, a su cuidado en no falsear la realidad. Esto le llevó en ocasiones a realizar ilustraciones del tipo de croquis militar, con indicación de las posiciones de las tropas en diversos momentos del conflicto. Este tipo de dibujo guarda relación con la pintura analítica de batalla desarrollada en el siglo XVII, y más ampliamente en el siglo XVIII, de finalidad pedagógica, tan en consonancia con la mentalidad racionalista de la época; se llega incluso a designar con letras elementos del cuadro, como en una figura de texto científico (La Batalla de la Montaña Blanca, Chiesa di Santa Maria della Vittoria, Roma). Un ejemplo de grabado analítico de Pellicer es la estampa "Combate del 25 de Febrero: Aspecto general», marzo 15, 1874 (Fig. 12), donde describe la retirada a Somorrostro, entrada la noche después de aquella sangrienta batalla; en el avance a S. Pedro de Abanto había sido herido de bala de fusil, aunque no gravemente, el general Primo de Rivera, quien aparece en primera línea sobre una camilla, rodeado por tres oficiales. pág. 143.

13 Antonio Gallego Gallego, Historia del grabado en España. Madrid, Cátedra, 1979, 
La obsesión de Pellicer por la información, por la realidad objetiva, le llevó a veces a indicar no sólo la fecha sino además la hora en que realizó el dibujo (“Interior de un Hospital», IEA, marzo 22, 1874) (Fig. 13). Las revistas mismas mantenían también una cierta objetividad publicando grabados sobre ambos bandos (aquí el republicano y el carlista) aún cuando en comentarios y editoriales tomasen partido por uno de ellos. A este respecto, conviene señalar que el carácter puramente informativo de la representación bélica fué un hallazgo del periodismo gráfico. En la pintura de Historia decimonónica, así como en anteriores épocas, el tema bélico era motivo exclusivo de exaltación, propaganda o pedagogía (en La Batalla de San Romano la objetividad se explica por su carácter de escenificación de torneo, y en Goya o Delacroix se llega tan sólo a la denuncia o la proclama social). La ilustración bélica en las revistas nos parece así mucho más cercana a la naciente fotografía que a la coetánea pintura de Historia; la ilustración retiene sin embargo un elemento de subjetividad que sólo la cámara llegaría a suprimir. Por otra parte, el reportaje bélico y, en general, de acción sólo se mantuvo mientras la fotografía, que "no convive fácilmente con los otros modos icónicos de representación, sino que, literalmente, tiende a devorarlos", careció de capacidad de instantánea ${ }^{14}$.

Obsérvese que si fué el Estado el que en el siglo XIX "promovió el género histórico como forma ideal de expresión oficial" y la alta burguesia la que «propició el retrato, reflejo románticamente egocentrista de sí mismo" ${ }^{15}$, fué la creciente clase media, ávida de información, la que originó el periodismo gráfico de las revistas de actualidad. El grabado jugó un papel tan crucial en la difusión de la noticia, como en otros campos de la información ${ }^{16}$ (por ejemplo, en Arqueologia, con los dibujos de E. Flandin sobre los descubrimientos de Nínive).

\section{LA ESCENA NOCTURNA EN LOS GRABADOS DE PELLICER}

Es sabido que José Luis Pellicer se consideró a sí mismo un pintor fracasado, incapaz de dominar el color, y que huyendo de él se refugió

14 Juan Antonio Ramirez, Medios de ..., pág. 137.

15 José Enrique Garcia Melero, «Pintura de Historia y Literatura Artística en España». Fragmentos, Núm. 6, Madrid, 1985, pág. 50-71.

${ }_{16}$ William M. IVins, Imagen impresa y conocimiento. Análisis de la imagen prefotográfica. Barcelona, Gustavo Gili, 1975, pág. 14 y 15. 
en la ilustración. "Ya que estamos condenados a hacer monigotes ... hagamoslos 10 mejor que podamos. ¿A qué engañarnos en que sólo pintando se puede ser artista y consumir miserablemente la existencia embadurnando telas? No: también dibujando se puede hacer arte; y hay que poner todo nuestro esfuerzo para conseguirlo y para que el público se convenza de ello" ${ }^{17}$.

Hay antecedentes de este drama en la Historia del Arte, el de Ingres casi coetáneo. Como observó Baudelaire "un dibujante es un colorista fracasado. Esto es tan verdadero, que Ingres, el representante más ilustre de la escuela naturalista en el dibujo, está siempre a la caza del color. ¡Admirable y desgraciada obstinación! Es la eterna historia de las gentes que venderían la reputación que merecen por aquélla que no pueden obtener. Ingres adora el color como una vendedora de modas" ${ }^{18}$. Contrariamente a Ingres, Pellicer, incluso en su etapa de pintor, habia evitado en algún caso el color refugiándose en la escena nocturna. Su lienzo más valorado, "Zitto ... silencio, che passa la ronda", segunda medalla en Madrid en 1871, en una escena tal. $Y$ curiosamente, hemos encontrado que entre sus dibujos del conflicto carlista más acabados hay un alto número de temas nocturnos, tratados con una gran variedad de estilos.

Una escena nocturna de carácter romántico es el grabado "La vispera de la batalla", junio 15, 1874 (Fig. 14), tomado in situ por Pellicer en las cercanías de San Pedro de Abanto al anochecer del 29 de abril. A las cinco de la madrugada del 30 se iniciaría la operación para liberar Bilbao, concluida en la tarde del 2 de mayo con la entrada en la capital vizcaína de la primera columna del ejército libertador; según el plan del consejo de generales, Concha debía atacar las posiciones del enemigo en las alturas de Galdamés, Serrano las de S. Pedro de Abanto y Laserna las de Sopuerta y Mercadillo: «En la primera línea de avanzada, hacia la cumbre de un monte cubierto de maleza y erizado de breñas, aparece la negra silueta de vigilante centinela, destacándose en el fondo de opacas nubes, apenas iluminadas por los últimos resplandores del crepúsculo. Detrás de aquel monte se extienden las trincheras del enemigo: los clarines de guerra anuncian la proximidad de la batalla, y como horribles mensajeros de las escenas de exterminio que habrán de representarse en breve, cruza por el aire espesa bandada de cuervos". La

17 Apeles Mestres, "Pellicer". La Lectura. Vol. 1, 1902 , pág. 587-595.

18 Charles Baudelaire, Curiosidades estéticas. Madrid, Ediciones Júcar, 1988, pág. 91 y 92. 
melancolía de la escena, tan afín al carácter de Pellicer, se enfatiza en el relato, lleno de sensibilidad romántica, intimista, es el diálogo del hombre solo con la naturaleza; hay como una correspondencia entre la lirización del texto y su proyección artística en el paisaje, con una escenografía crepuscular de gran tradición literaria que nos recuerda al romántico Caspar David Friedrich, y en particular a su cuadro "Dos hombres contemplando la Luna", tan semejante en composición al grabado de Pellicer.

Esta armonía entre lo que el artista ilustra y lo que escribe se repite en la escena de crepúsculo "Abrevando caballos del segundo cuerpo del ejército en Arga, cerca de Larraga", marzo 15, 1875 (Fig. 15). Hay en este dibujo al aire libre, con sus juegos de luces y reflejos en el agua, un fondo poético, una sensibilidad nueva que nos hace pensar en los impresionistas, y en Degas, en cuanto al tema, en particular. "Representa un animado episodio de la vida del soldado en campaña. La vista está tomada en las cercanías de Larraga, a orillas del río Arga y hacia la caída de la tarde, hora en que, según costumbre, se lleva al abrevadero los caballos del ejército. El cuadro es de efecto sorprendente. Escóndese el sol detrás de los lejanos montes, y apenas sus postreros rayos se reflejan en el agua del manso rio; las siluetas opacas de los caballos, montados unos (porque tal vez acaba de llegar algún destacamento) y del diestro o sueltos los demás, se destacan en el fondo oscuro de la noche que empieza, y se agitan en confuso movimiento, por el río, por las márgenes, por la pradera cercana". La escena nos acerca a la pintura paisajística de la escuela de Olot (Pellicer había sido condiscípulo de Vayreda con Martí Alsina).

En algún caso, el tremendismo incipiente de Pellicer asoma muy claramente, como en el dibujo "Un vivac en Monte Esquinza", abril 22, 1875 (Fig. 16). La pobreza del vivac que se nos muestra hace pensar en Baroja y su escena final de miseria urbana, "Las calderas del asfalto" en La Busca (la imagen de un vivac está en boca de uno de los golfillos que pasan la noche junto a las calderas, en la Puerta del Sol: "Dormimos como en campaña») ${ }^{19}$. Técnicamente, interesa observar la desigual intensidad del entintado en la parte alta de la franja central de la estampa. Cuando el grabador quería conseguir un efecto delicado en aiguna parte del dibujo, raspaba esa área para que en la impresión sufriese menos presión que otras partes vecinas y, en consecuencia, quedara más clara. En nuestro grabado el efecto no es naturalmente intencional, y se debe

19 Pío Baroja, La Busca. Madrid, Caro Raggio, 1973, pág. 290-292. 
sin duda a una unión defectuosa de los bloques, por lo que la parte alta central quedó ligeramente rebajada (obsérvese que en la unión con la franja izquierda de bloques el número de incisiones y su grosor es igual a ambos lados, lo que impide explicar la desigual intensidad del entintado por diferencias en la grabación). Como en el dibujo del Duque de la Torre antes mencionado, también aquí se pueden apreciar las líneas blancas producto de un mal encaje de los bloques.

La estampa «Combate en el cerro de Muniain (Pico de Villatuerta), el 3 del actual», febrero 28, 1875 (Fig. 17) representa el asalto de ocho batallones carlistas (cuatro según éstos) al cerro de Muniain, al Norte de Monte Esquinza, defendido por 200 hombres del regimiento de la Princesa y una sección de ingenieros. Monte Esquinza habia sido tomado dos días antes por tropas del segundo cuerpo del ejército del Norte al mando de Primo de Rivera. La estampa exhibe un dibujo excepcional, expresionista, cargado de horror. Pellicer introduce aquí nuevas formas próximas al naturalismo y al tremendismo. No hay héroes en esta violenta pelea de aldea. Nada más lejano de la quietud de los nocturnos anteriores. Como la fotografía haría en la conflagración de 1914, Pellicer rompe, con esta escena, cualquier imagen romántica o gloriosa de la guerra y hace imposible el dudar que utambién dibujando se puede hacer arte». 


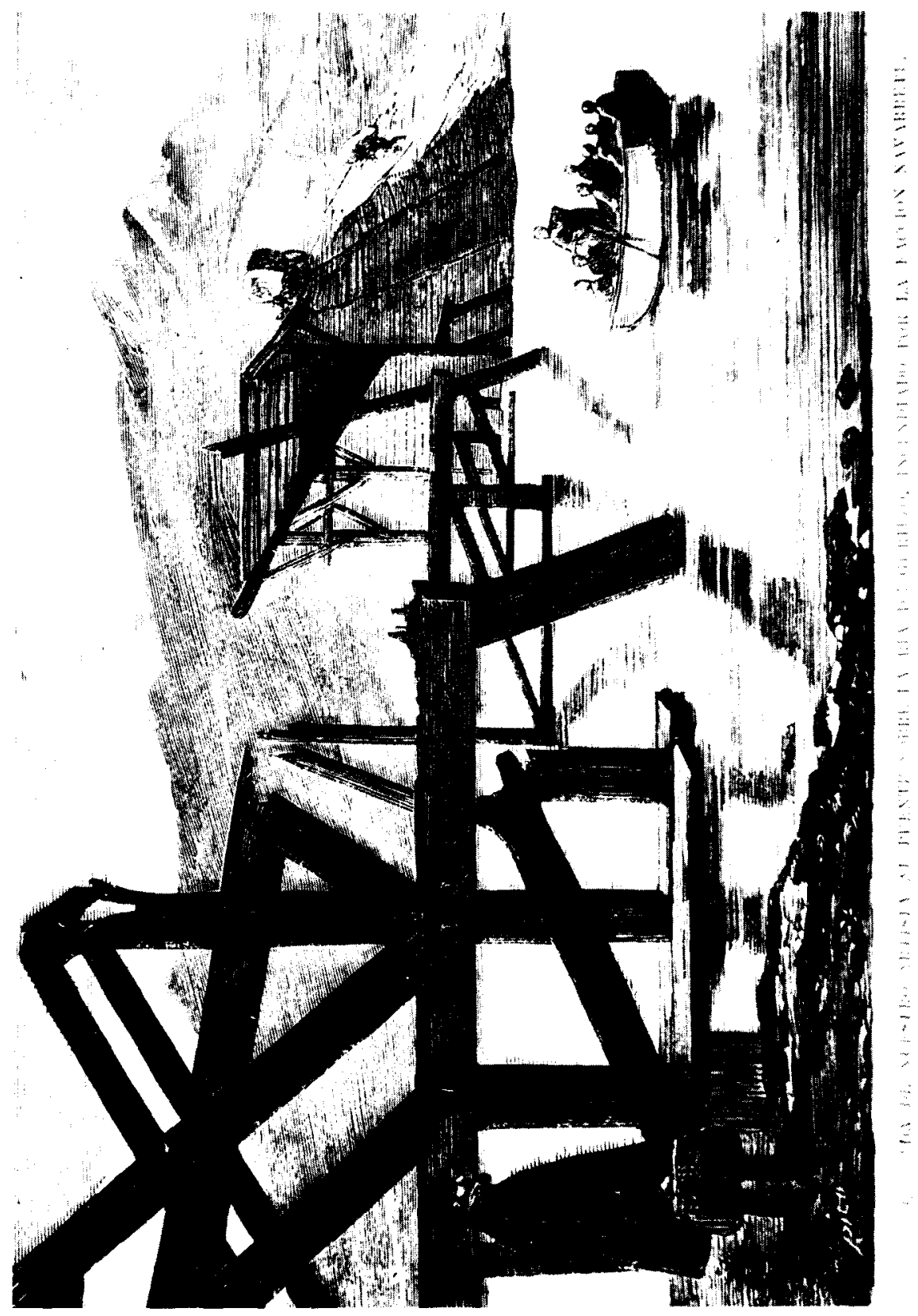

Fig. 1. La Ilustración Española y Americana, marzo 8, 1874 


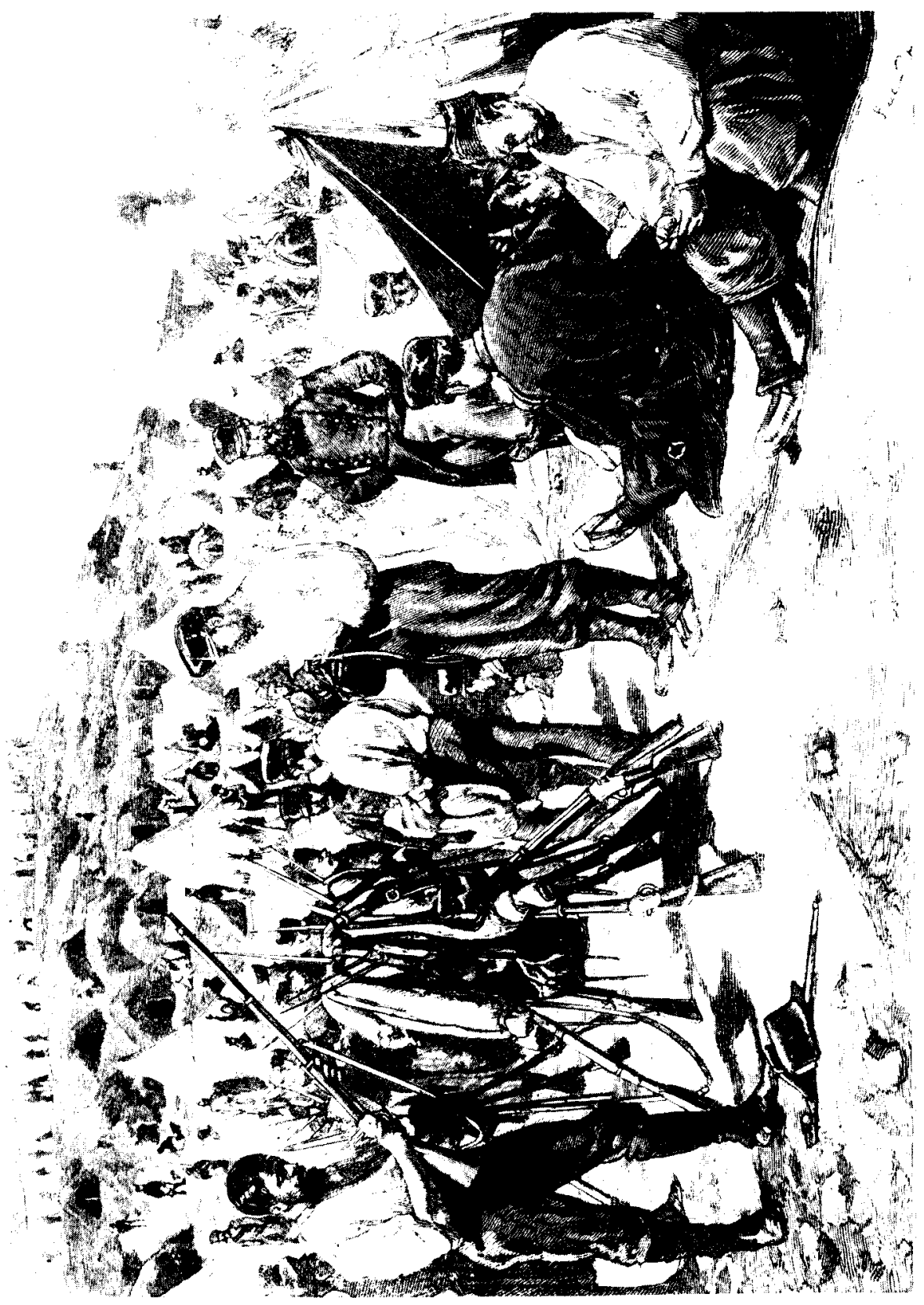

Fig. 2. Le Monde Illustré, febrero 12, 1876 


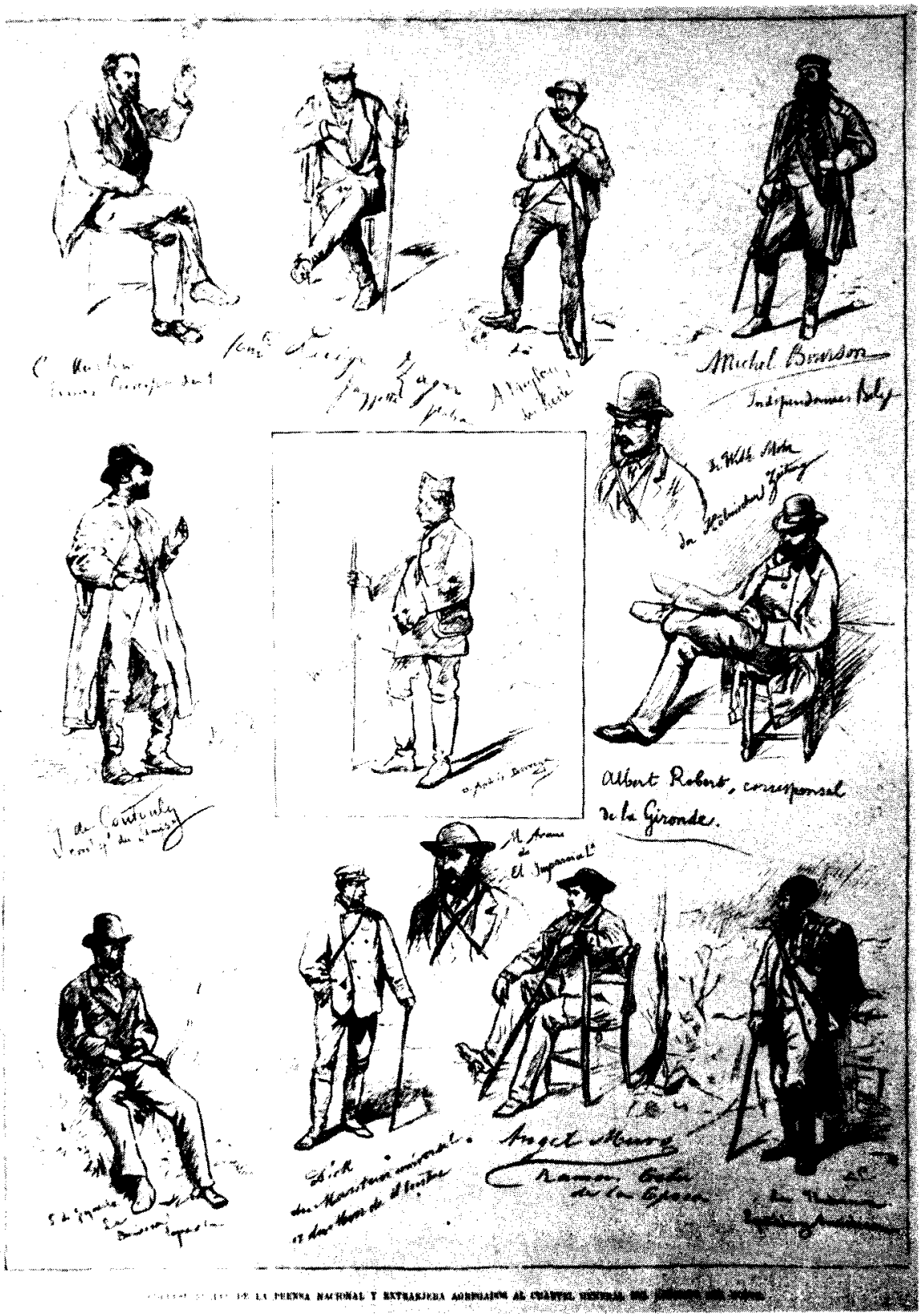

Fig. 3. I.E.A., mayo 22, 1874 


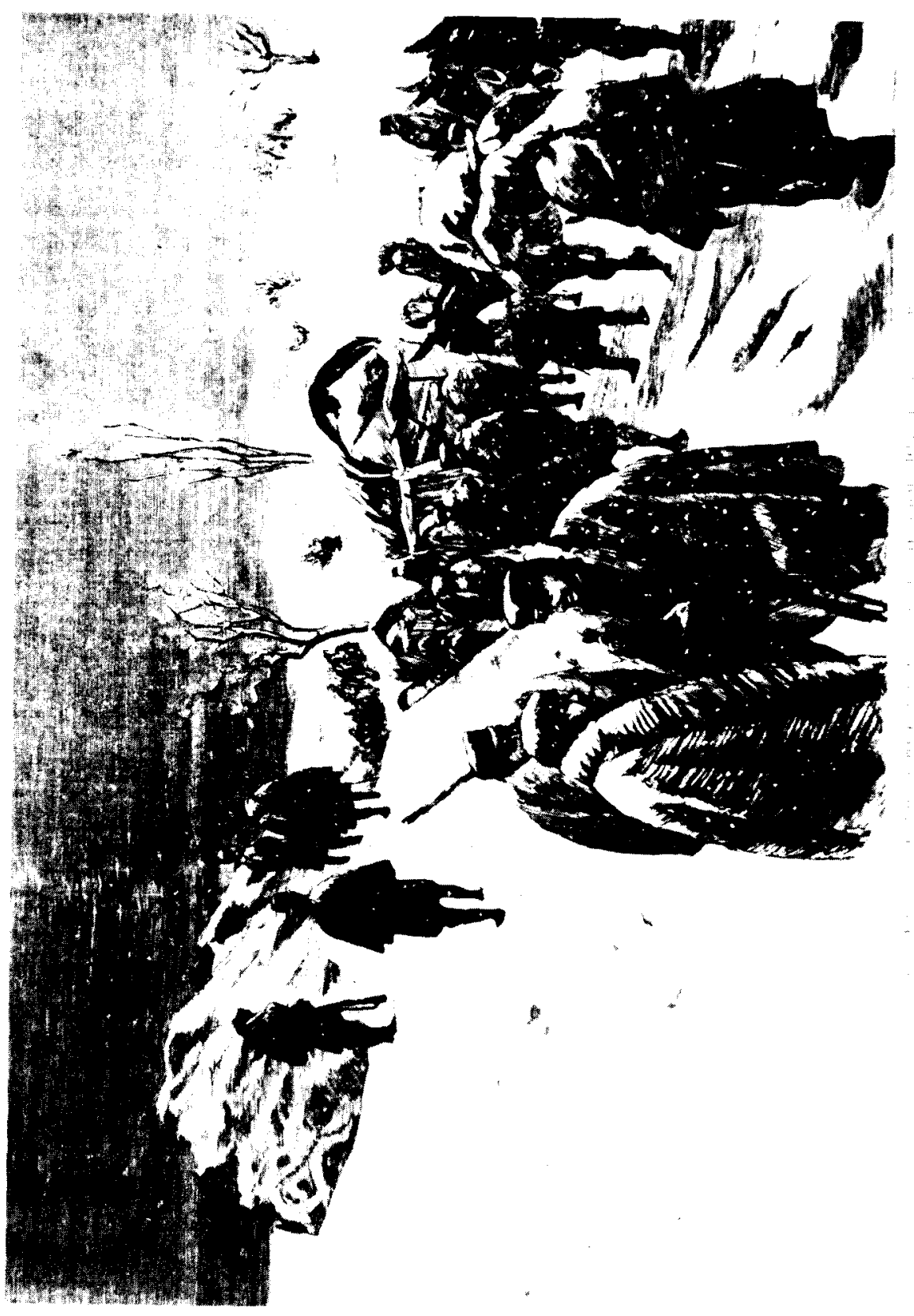

Fig. 4. I.E.A., febrero 22, 1876 


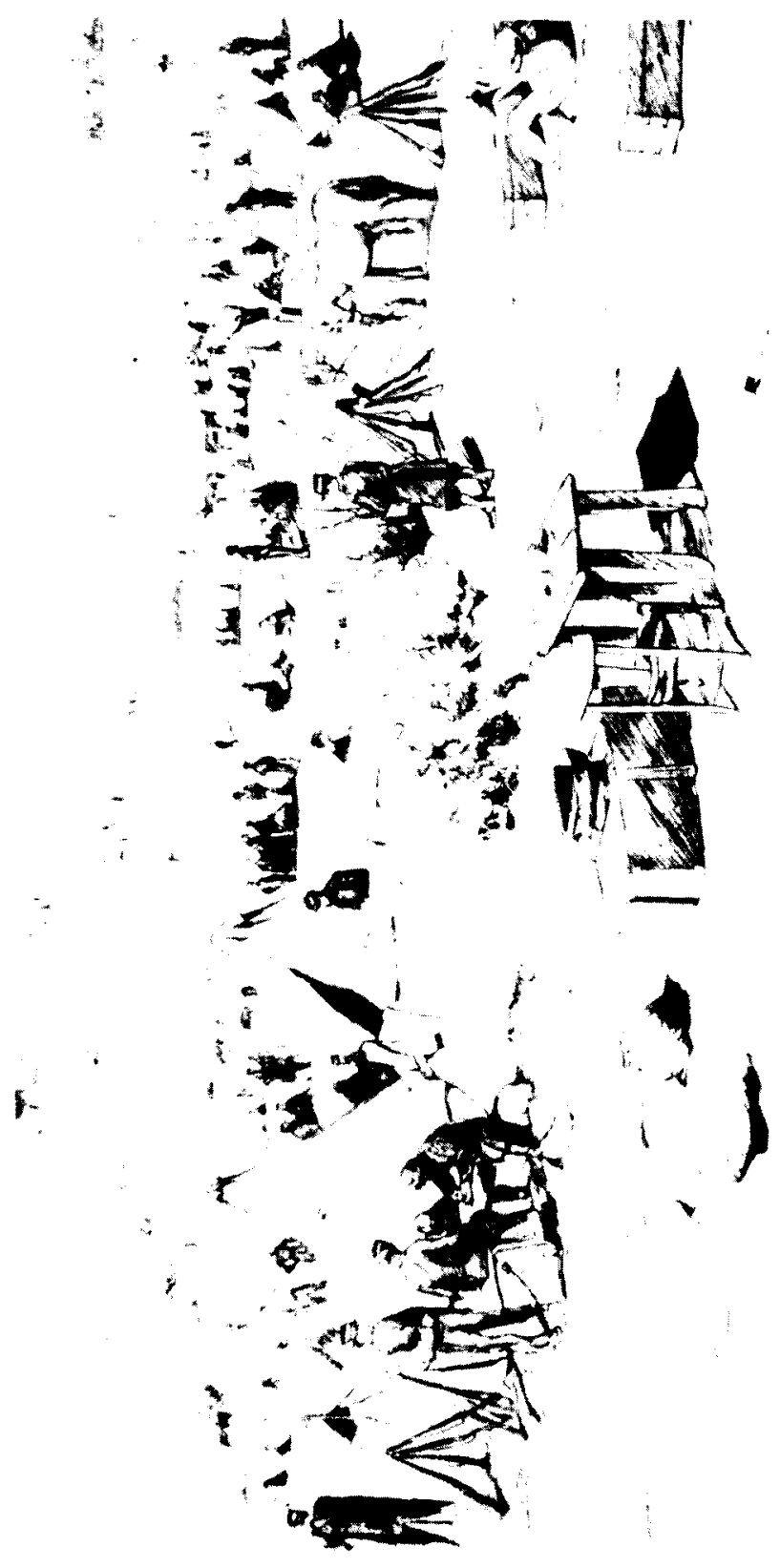

Fig. 5. I.E.A., mayo 22, 1874 


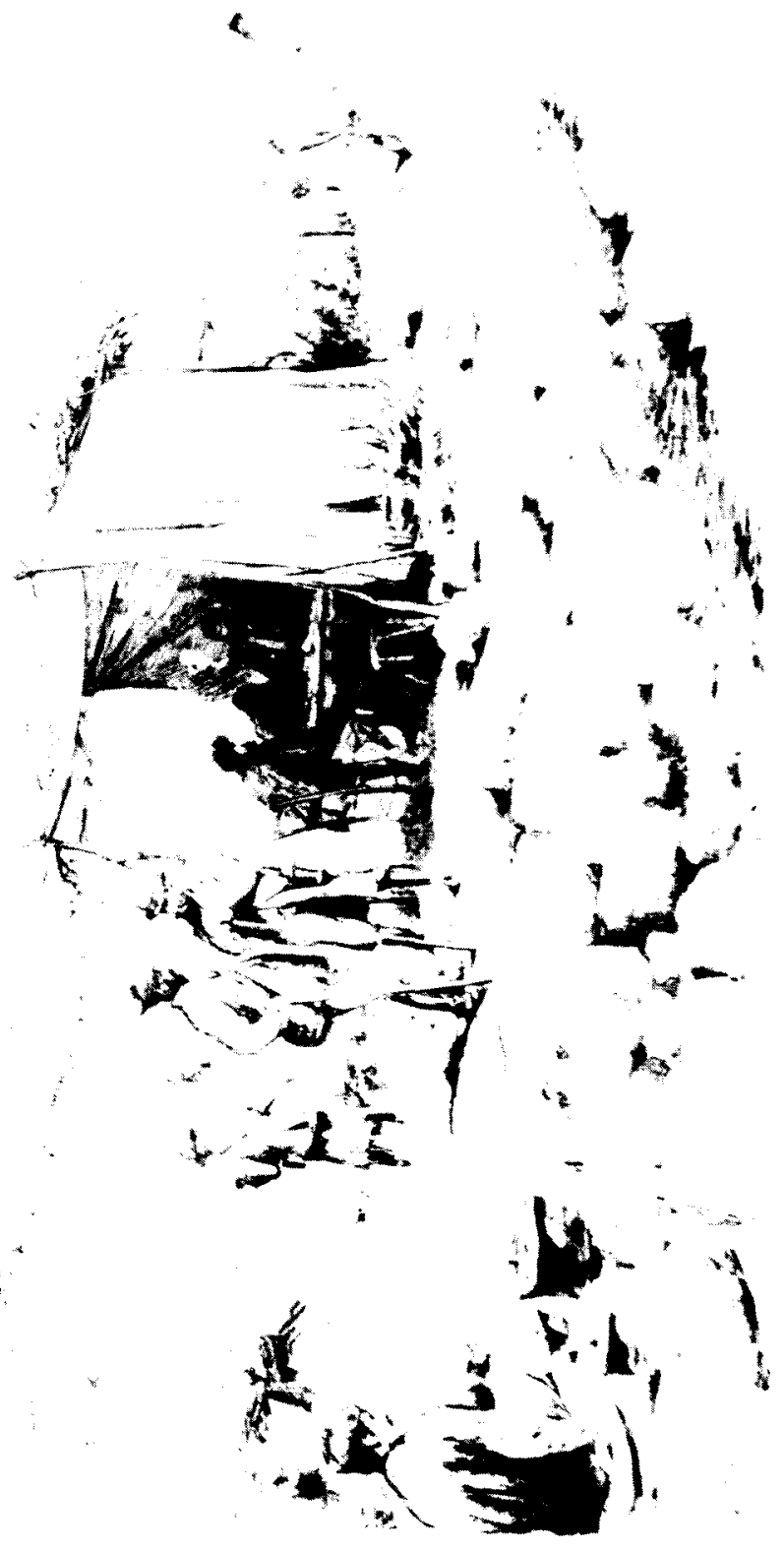

Fig. 5 bis. I.E.A., mayo 22, 1874 


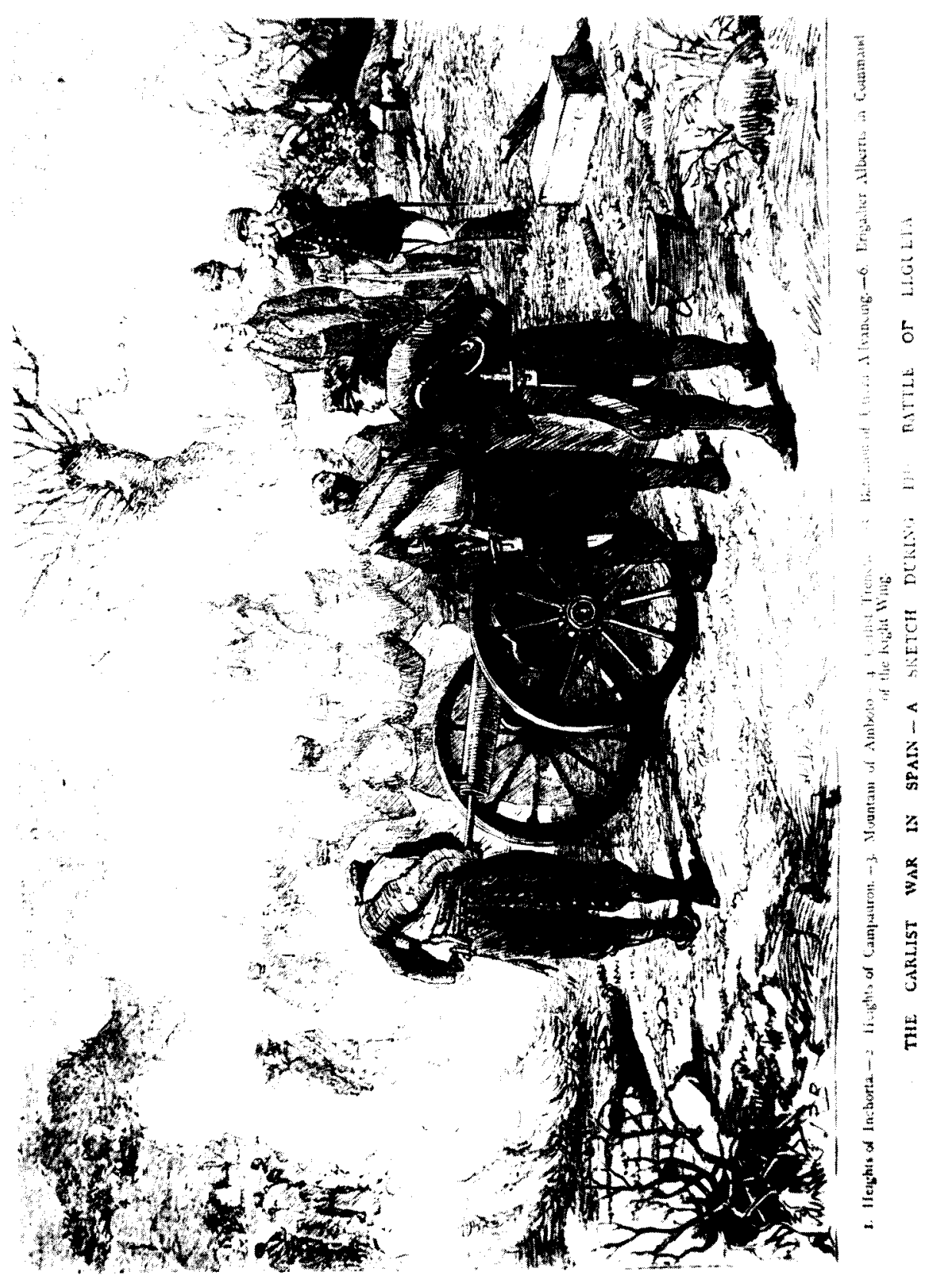

Fig. 6. The Graphic, marzo 4, 1876 


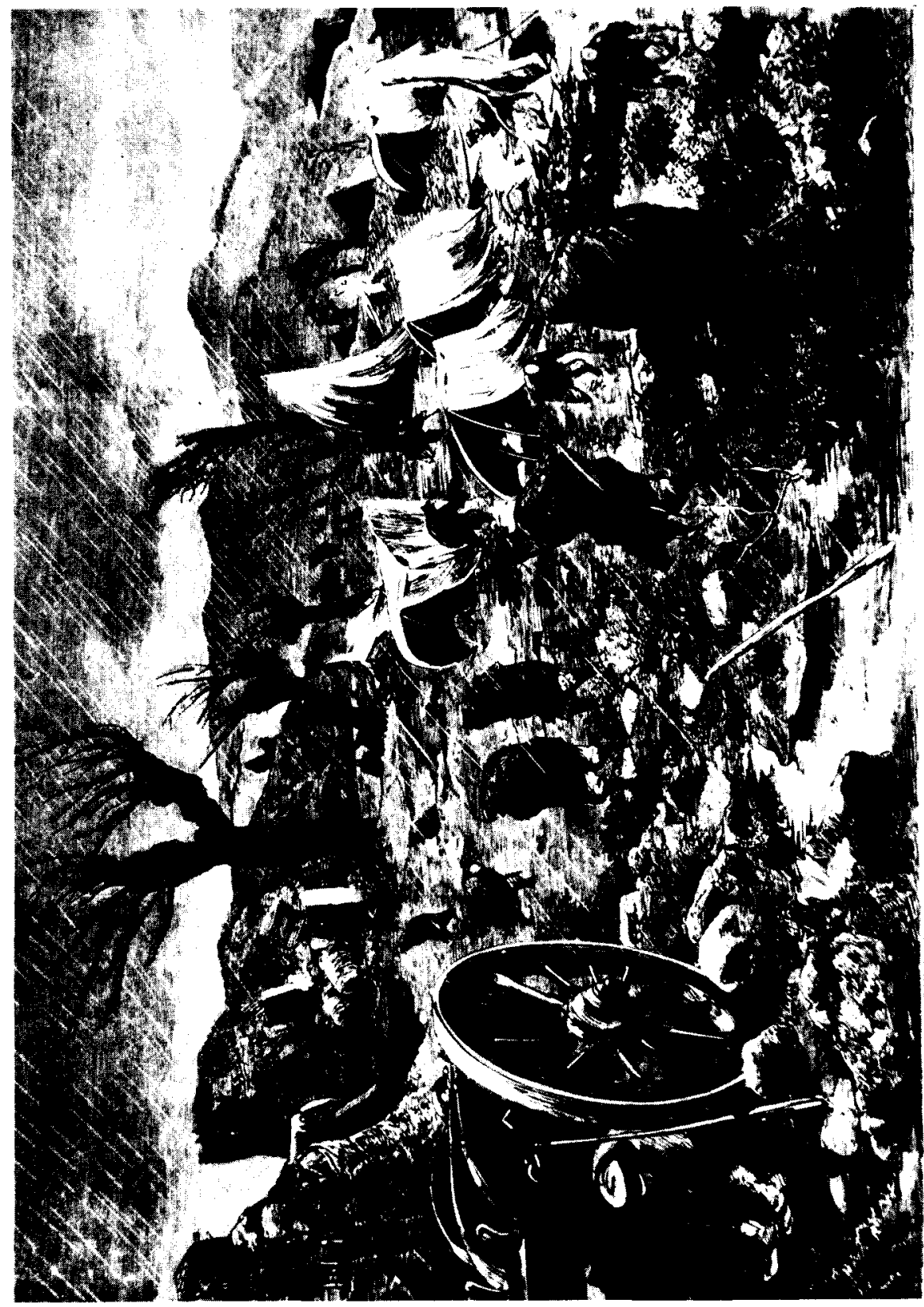

Fig. 7. I.E.A., $a b r / / 22,1874$ 


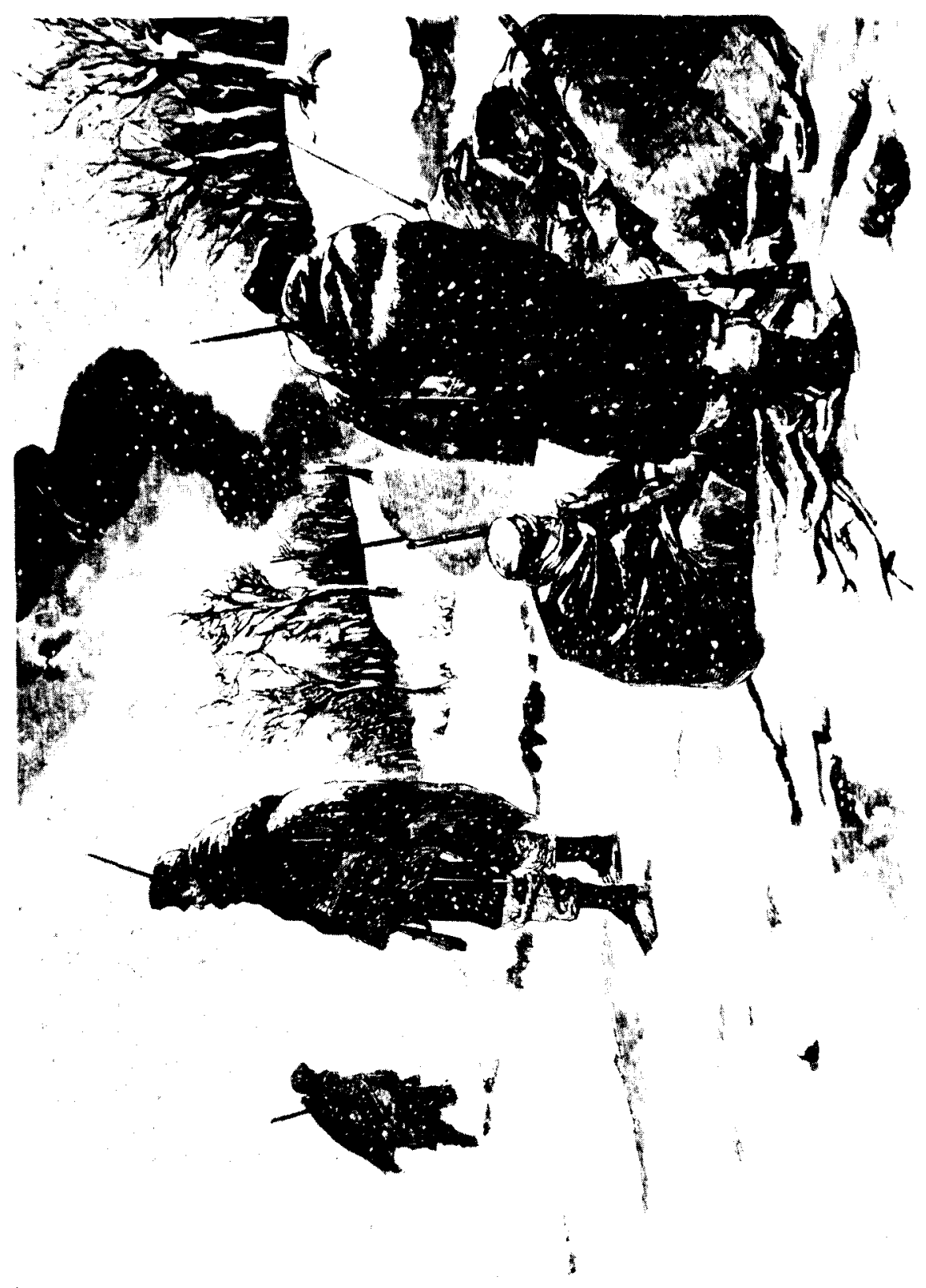

Fig. 8. I.E.A., febrero 15,1874 


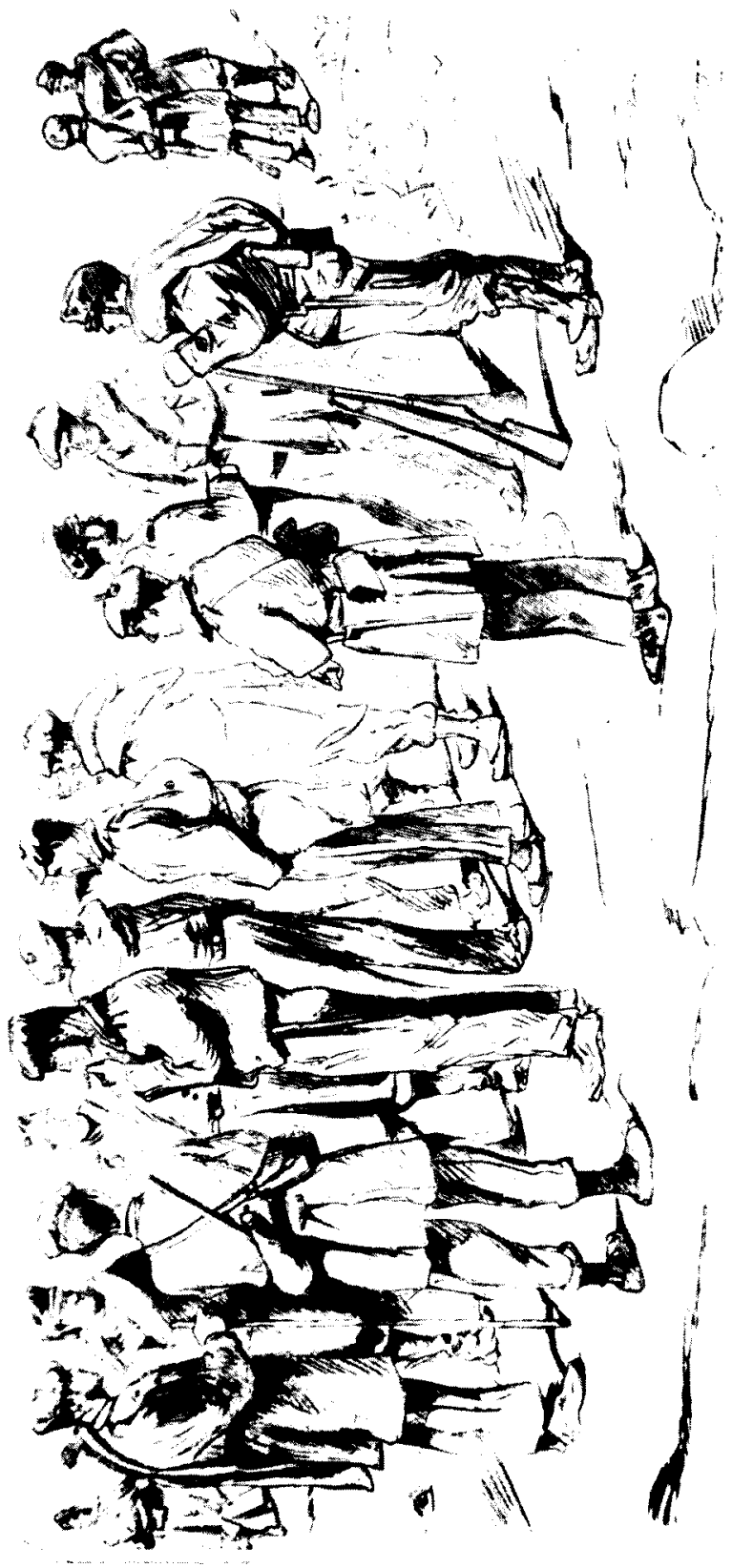

Fig. 9. I.E.A., abril 15, 1874 


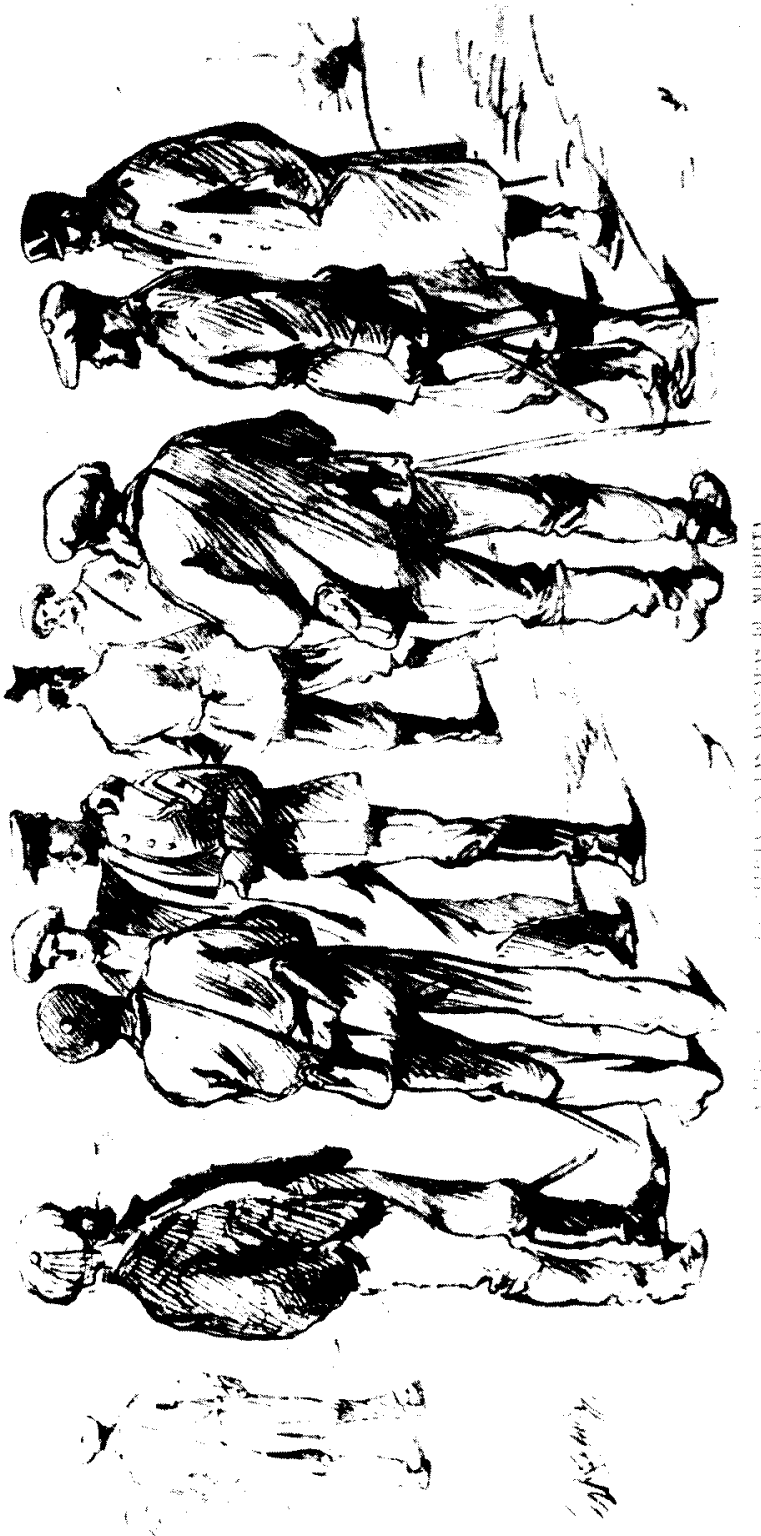

Fig. 9. bis. I.E.A., abril 15, 1874 


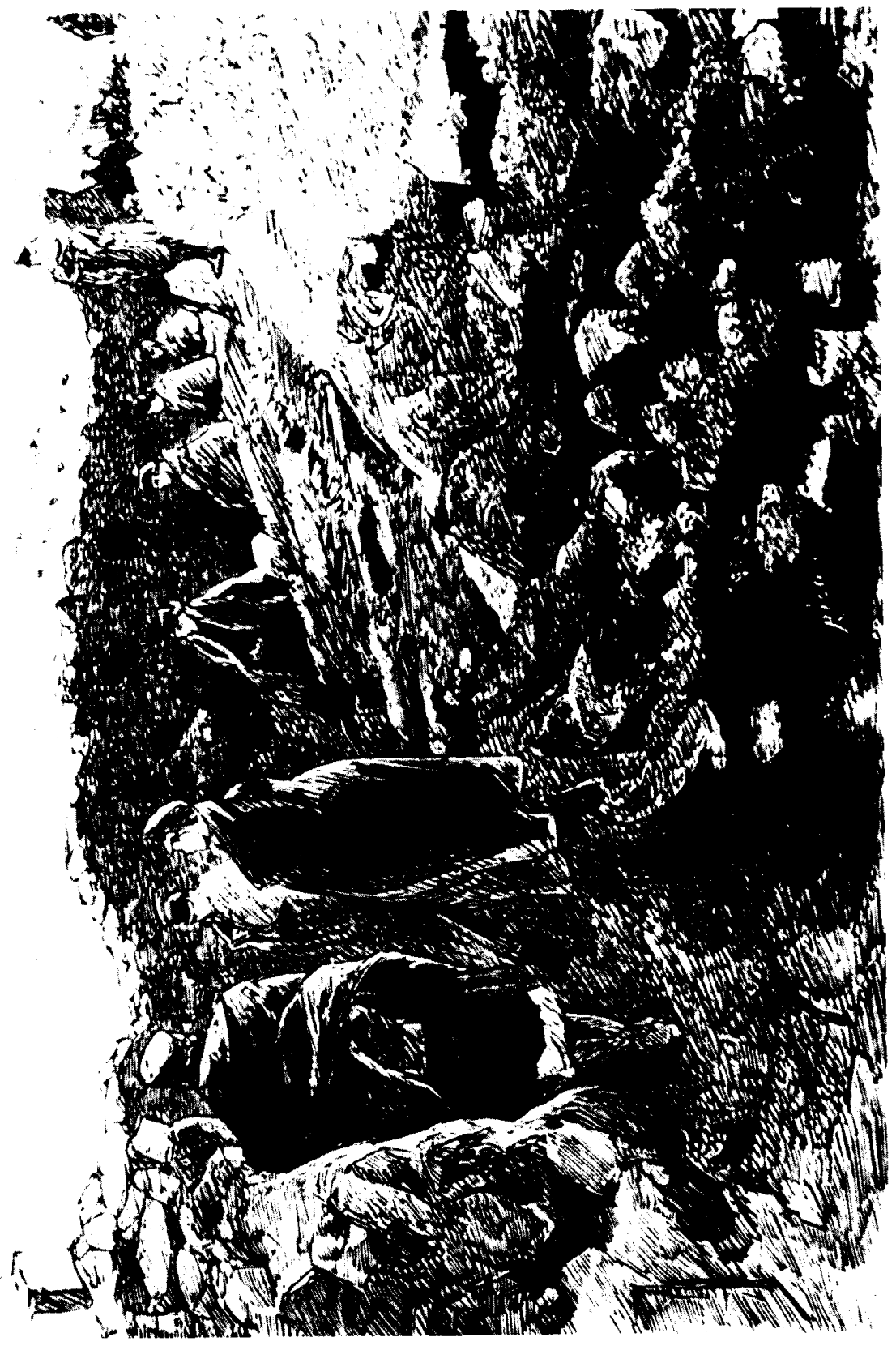

Fig. 10. I.E.A., abril 30, 1874 


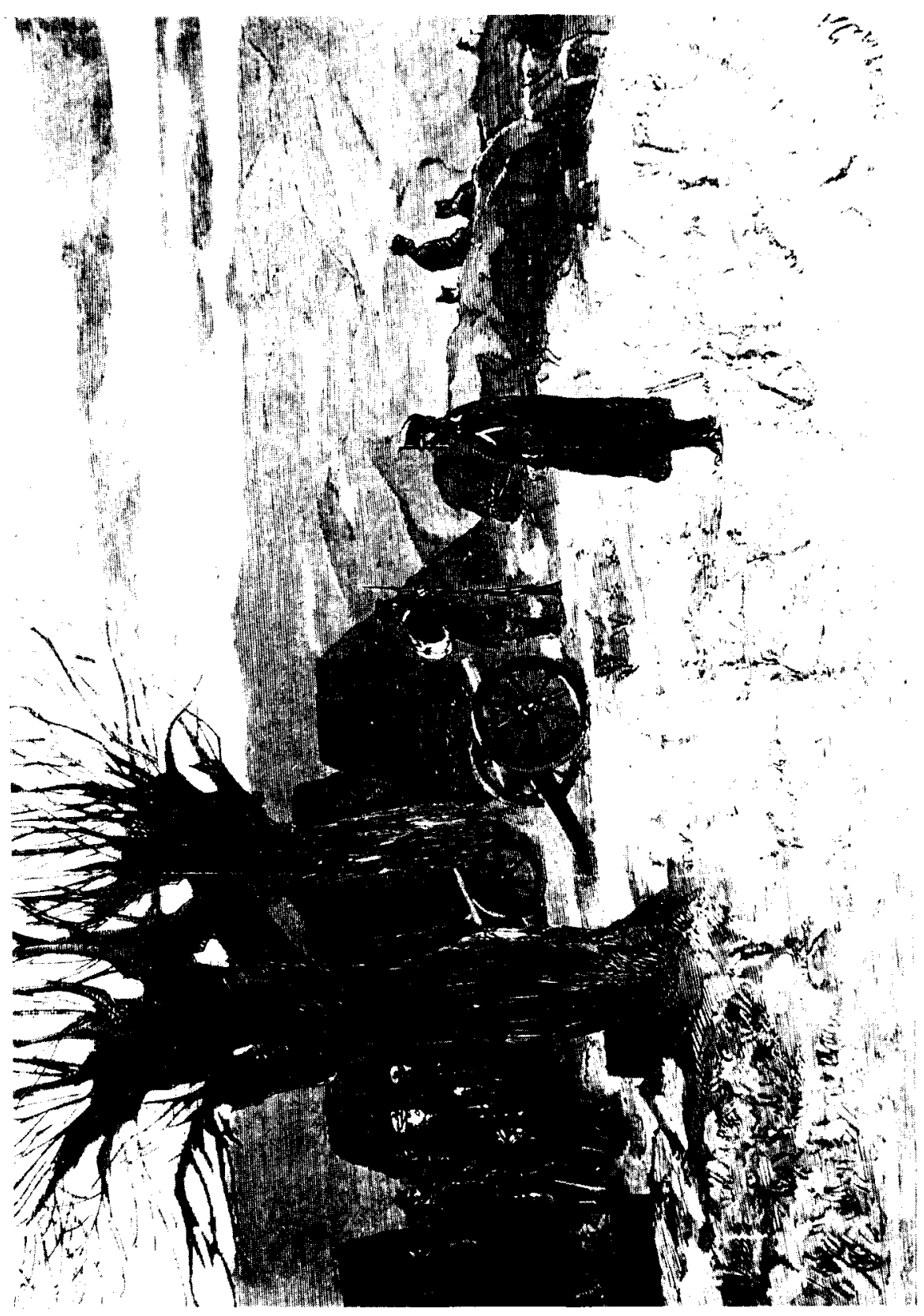

Fig. 11. I.E.A., marzo 30, 1874 

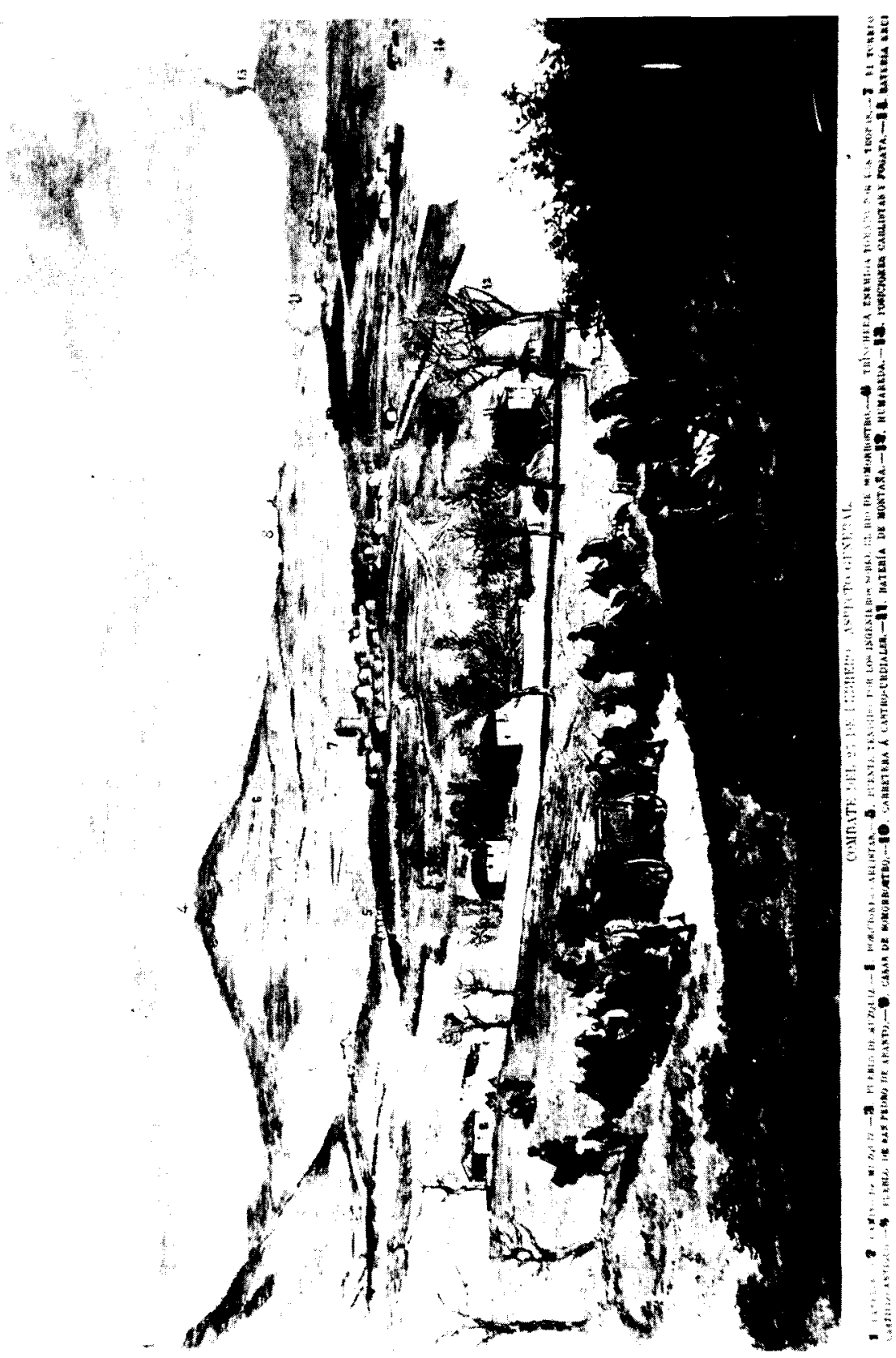

Fig. 12. I.E.A., marzo 15, 1874 


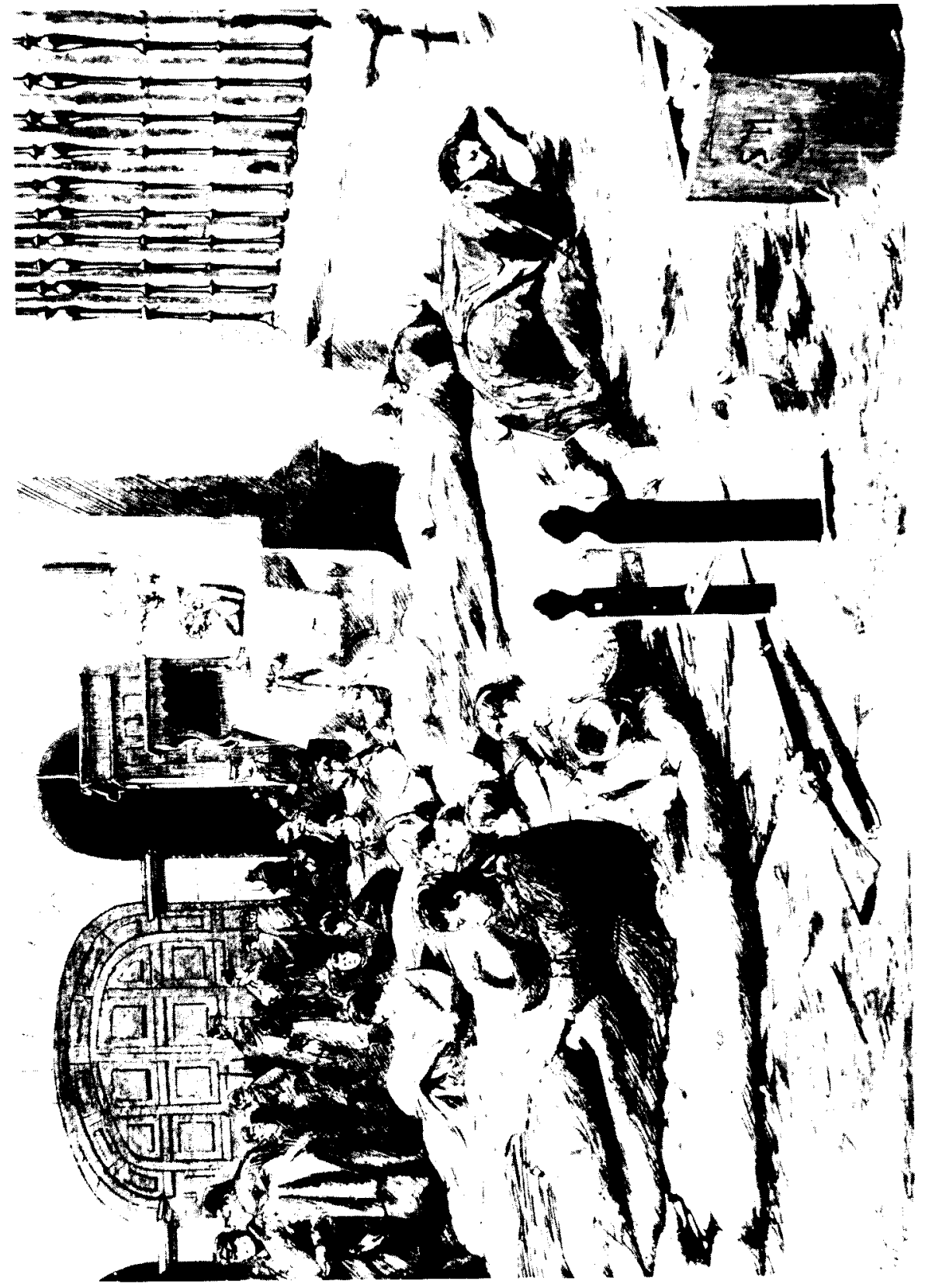

Fig. 13. I.E.A., marzo 22, 1874 


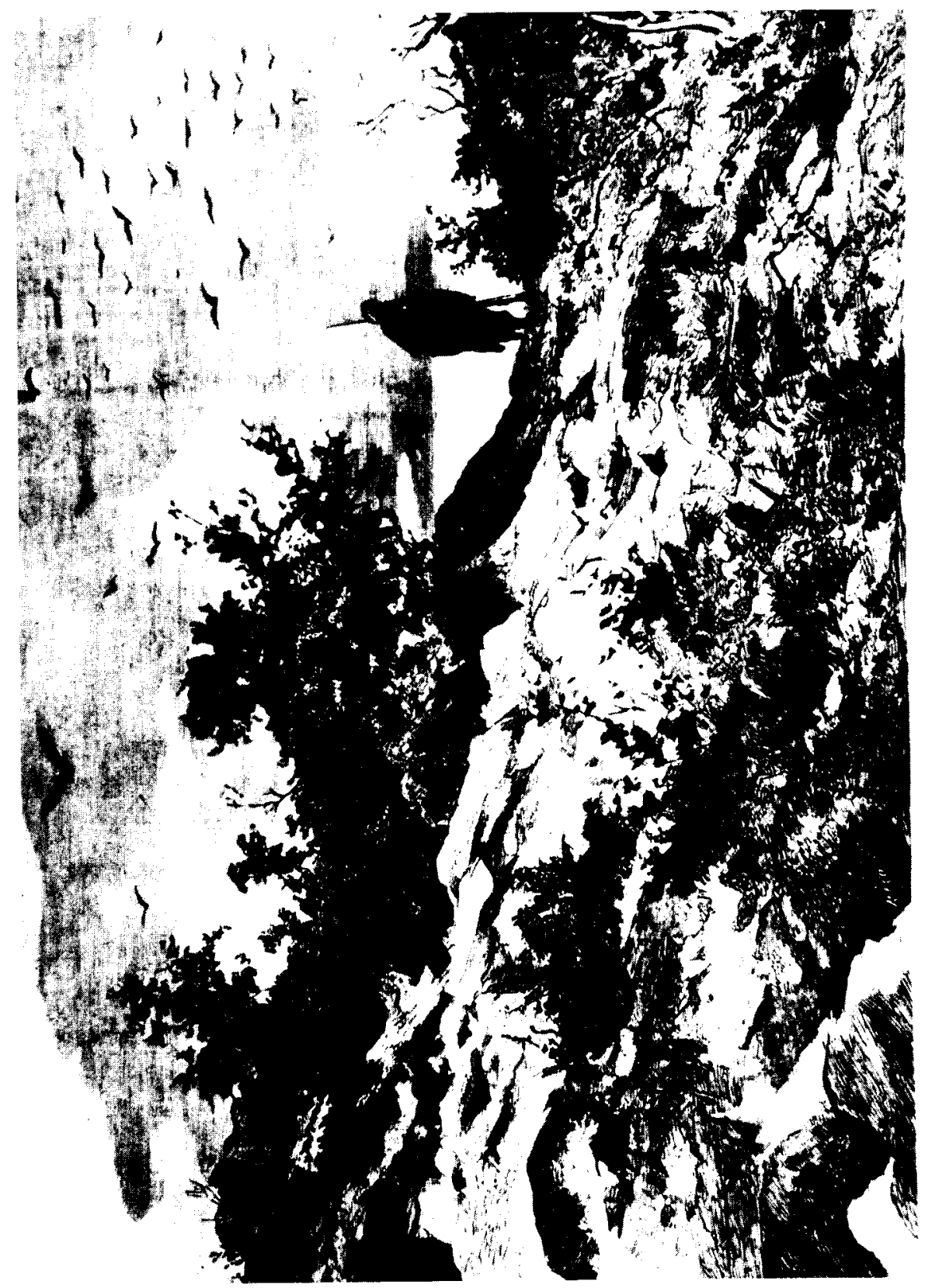

Fig. 14. I.E.A., junio 15, 1874 


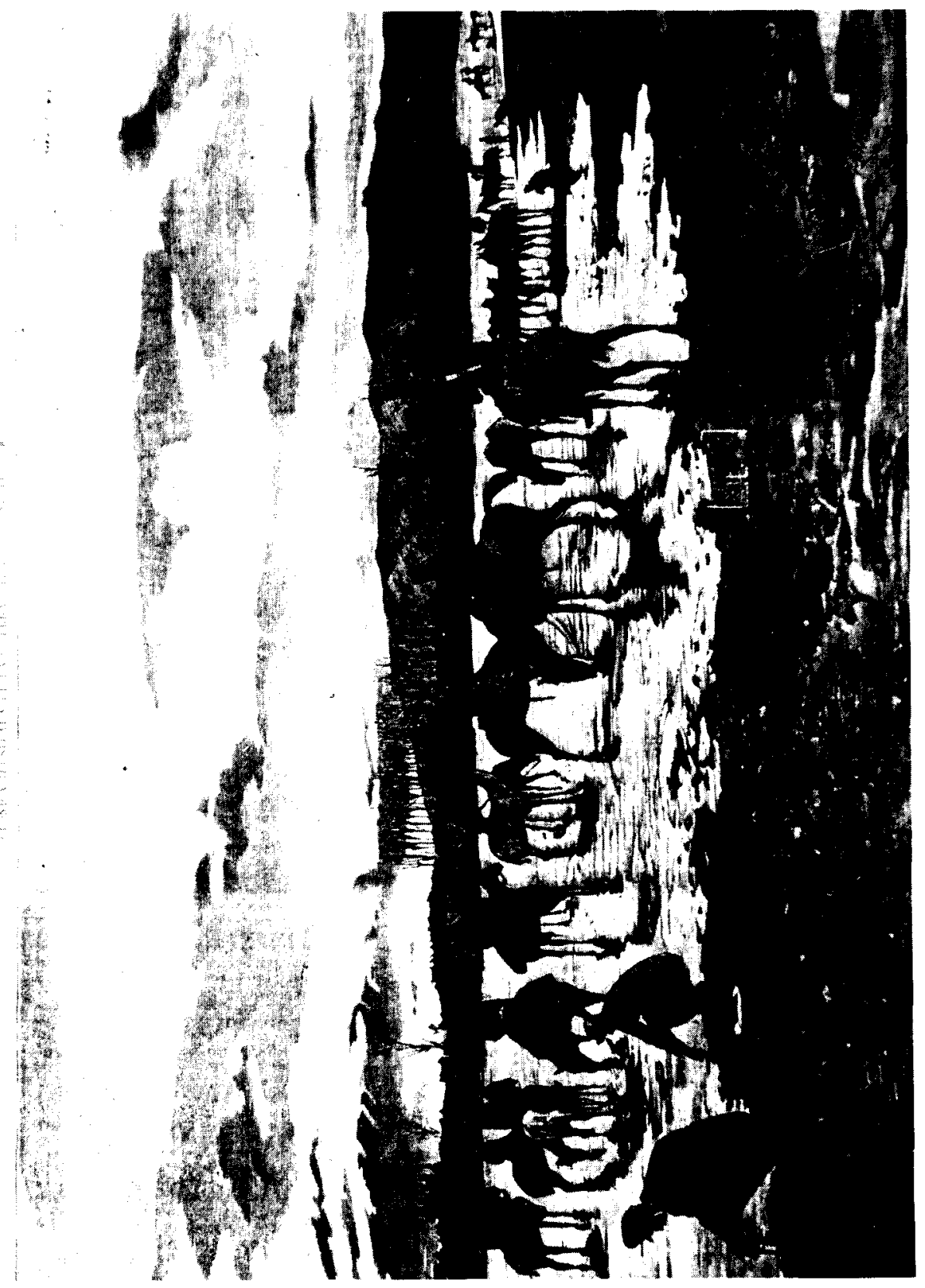

Fig. 15. I.E.A., marzo 15, 1875 


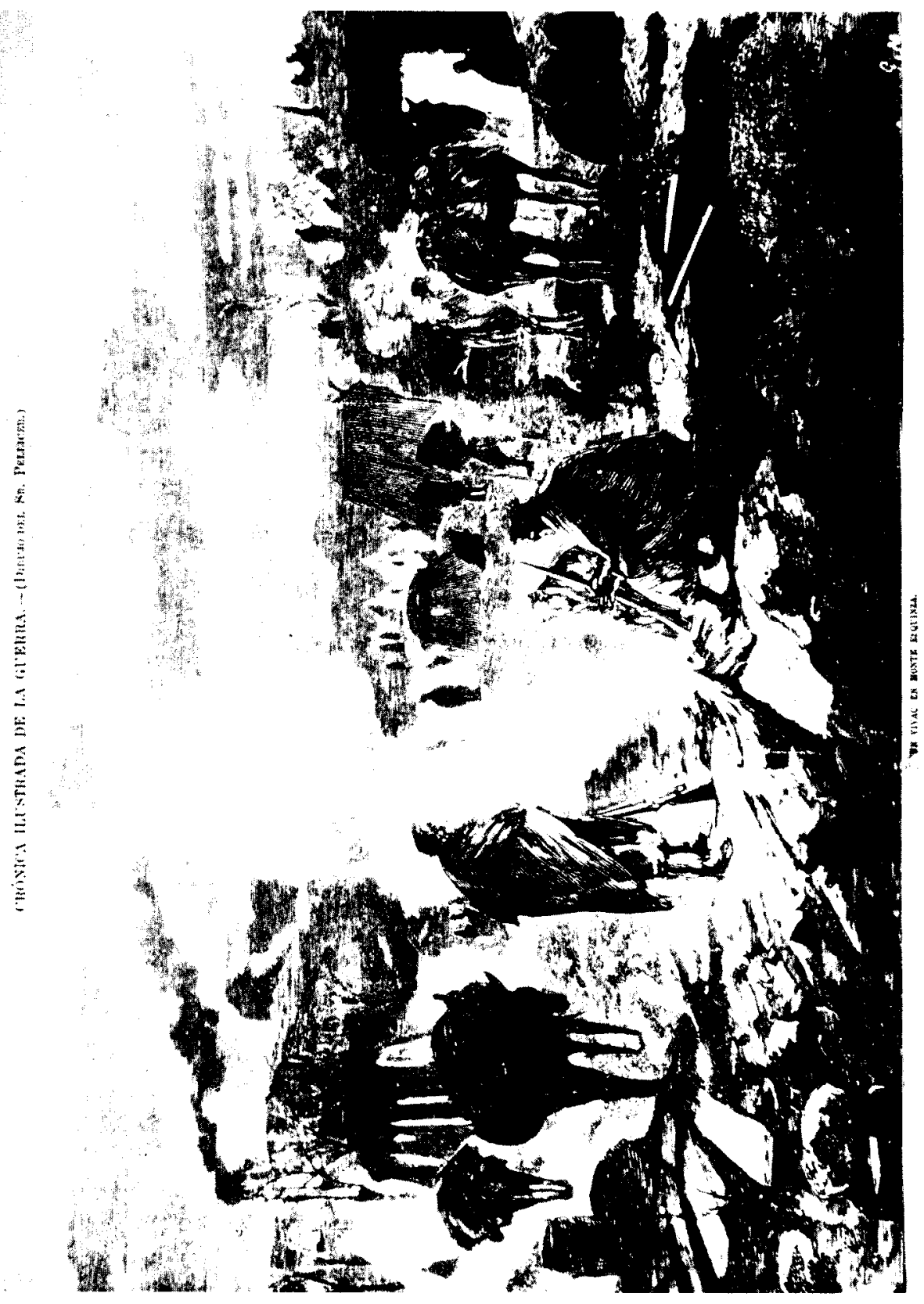

Fig. 16. I.E.A., abril 22, 1875 


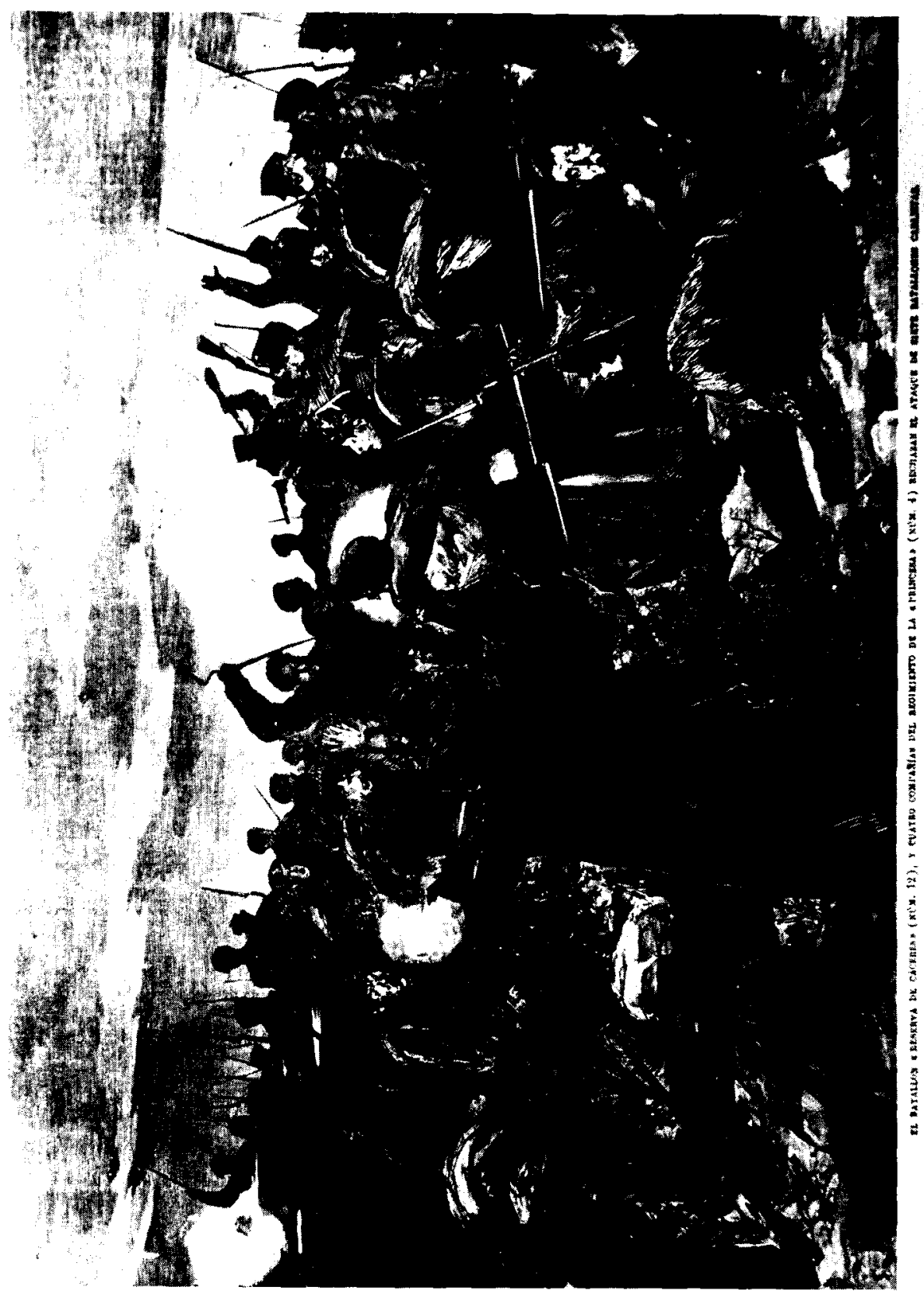

Fig. 17. I.E.A., febrero 28, 1875 